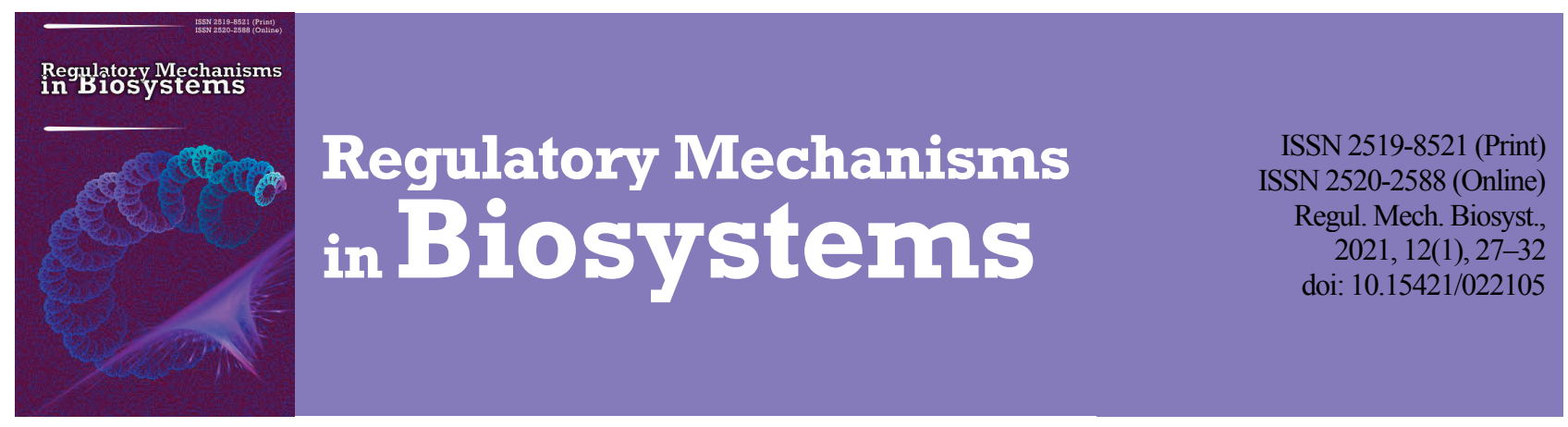

\title{
Microscopic changes in the organs of broiler chickens with Ornithobacterium rhinotracheale infection
}

\author{
B. V. Borysevych*, V. B. Dukhnytskyj*, A. M. Tyshkivska*, M. Y. Tyshkivsky**, N. V. Tyshkivska** \\ *National University of Life and Environmental Sciences of Ukraine, Kyiv, Ukraine \\ **Bila Tserkva National Agrarian University, Bila Tserkva, Ukraine
}

Article info

Received 23.01.2021

Received in revised form 17.02.2021

Accepted 19.02.202

National University of Life and Environmental Sciences of Ukraine, Heroyiv Oborony st., 15/3, Kyiv, 03041, Ukraine Tel: + 38-068-678-54-18.

E-mail:

annatyshkivska@gmail.com

Bila Tserkva National Agrarian University,

Sobornapl., $8 / 1$,

Bila Tserkva, 09117, Ukraine

Tel: $+38-097-525-29-6$

E-mail:

tyshkivkymikhailo@gmail.com

Borysevych, B. V., Dukhnytskyj, V. B., Tyshkivska, A. M., Tyshkivsky, M. Y., \& Tyshkivska, N. V. (2021). Microscopic changes in the organs of broiler chickens with Ornithobacterium rhinotracheale infection. Regulatory Mechanisms in Biosystems, 12(1), $27-32$. doi:10.15421/022105

Nowadays ornithobacteriosis is widespread among industrial poultry in Ukraine and the world. The disease leads to significant economic losses. The large variation in the serotypes of the bacteria complicates the treatment of the disease. The study of microscopic changes that occur in organs during ornithobacteriosis will help to better understand the pathogenesis of the disease development. Ornithobacteriosis was diagnosed in clinically sick broiler chickens by bacteriological studies using Maldi Tof mass-spectrometry. As a result of the antibiotic sensitivity test, the pathogen was found to be sensitive to doxycycline, tilmicosin, rifampicin, cefazolin, amoxiclav and benzylpenicillin. Histological studies of internal organs - trachea, lungs, heart, kidneys, liver and spleen - were carried out. It was found that with spontaneous ornithobacteriosis of broiler chickens, the most expressive microscopic changes occur in the respiratory organs the lungs and trachea and are characterized by a decrease in the lumen of the parabronchials due to edema of their walls and infiltration with lymphocytes, the absence of epithelium on the surface of the parabronchials, narrowing of the air capillaries of the parabronchial complexes, hemorrhages in the parenchyma of the parabronchial complexes, vasodilatation of the lung vessels and overflow of their blood vessels with blood cells, edema around the epithelium trachea, destruction of part of the tracheal mucosa epithelial cells, edema of its submucosa, expansion and overflow of blood vessels of the mucous membrane with blood cells. In the spleen there was a uniform diffuse edema of the parenchyma and a decrease in the number of lymphocytes in the lymphoid follicles; in the kidneys - expansion and overflow of the stroma blood vessels, uneven edema of the glomeruli of one part of the renal corpuscles and destruction of the glomeruli of another, granular degeneration of the convoluted and straight tubules of the kidneys; in the liver-edema, hemorrhage, violation of the hepatic lobules' structure, expansion of the hepatic veins, granular degeneration of hepatocytes or their destruction; in the heart - edema of the myocardial interstitium, muscle fibers' granular dystrophy, fragmentation of muscle fibers as a result of their rupture. Histological research of ORT infected chickens will lead to a better understanding the mechanism of pathological changes at the microscopic level, which will facilitate the development of more effective methods of treatment and prevention of the disease.

Keywords: ornithobacteriosis; respiratory diseases; broilers; microscopic changes; histological examinations; bacteriological research; sensitivity to antibiotics; Maldi Tof.

\section{Introduction}

Ornithobacteriosis (ORT) is a disease of the bird respiratory system, manifested by pneumonia, pleurisy, tracheitis and aerosaculitis. Chickens, turkeys, ducks, geese, pheasants, quails, pigeons, partridges and ostriches are susceptible to the disease (Barbosa et al., 2020). The causative agent Ornithobacterium rhinotracheale often acts as a secondary bacterial infection, which aggravates the course of other viral and bacterial diseases. It is diagnosed in cases of infectious bronchitis, laryngotracheitis, hemophilia, metapneumovirus infection, escherichiosis and aspergillosis (MoralesErasto et al., 2016; Chu et al., 2017; Ellakany et al., 2019).

Ornithobacterium rhinotracheale is a small, gram-negative bacillus with rounded ends, which does not form spores or capsules, is poorly cultured by classical bacteriological methods, and its growth is often suppressed by the accompanying microflora (Hauck \& Shivaprasad, 2015). The causative agent of ornithobacteriosis is common in Europe and Asia, and poultry are infected in vertical and horizontal ways (Mayahi et al., 2016; Xue et al., 2020). A large variation in ornithobacterium serotypes, the rapid development of circulating strains' resistance, the complex process of isolating the pathogen and setting up a response to antibiotic sensitivity, contributes to the fact that ornithobacteriosis often remains an "undertreated disease". The pathogen is localized in the trachea, air sacs and lungs. To date, $18(\mathrm{~A}-\mathrm{R})$ serovars of the pathogen have been isolated from birds from different countries and continents. The most pathogenic serovar, which is isolated from $90 \%$ of sick chickens and $50 \%$ of sick turkeys, is serovar A. Among others, in Germany, the circulation of serovar E is established in $20 \%$ of sick birds. Serovars, which do not occur often, accounted for about 10\%, including variants B and C (Szabó et al., 2017). There have been identified ornithobacteria serovars that have hemolytic activity, but with less pathogenicity compared to non-hemolytic strains (Thieme et al., 2016).

The pathogenic effect of most ornithobacteria is due to their ability to induce hydrolysis of glycoproteins due to neuromedial activity. The enzyme neuromediase is present on the surface of some viruses and bacteria, ferments oligosaccharides, glycoproteins, and glycopeptides, which ensures better penetration of the pathogen into the host organism (Rosa-Ramos et al., 2018; Barbosa et al., 2020). Variants of ornithobacteria with pronounced antibiotic resistance to most drugs and resistance to macrophages were also identified. This may be due to the ability of ornithobacteria to achieve interspecies cross-interaction due to conjugation, especially between serovars A and I, H and J (Oca-Jimenez et al., 2018). The pathological changes that are observed in ornithobacteriosis are usually localized to the lungs, and include thickening of the interstitial tissue, edema, effusion of exudate, fibrin, and heterophilic infiltration. In the trachea, as a rule, no 
specific pathological changes are observed, only sometimes lymphocytic, mononuclear infiltration of the mucous membrane, hyperplasia of the glandular epithelium are recorded (Gavrilović et al., 2015). A significant variation in the serovars of the pathogen and their variability significantly complicates the diagnosis of the disease in industrial poultry farming. The study of microscopic changes in organs that occur during the development of the disease is important for the rapid diagnosis of the disease. There is insufficient data on the antibiotic sensitivity of Ornithobacterium serovars circulating in Ukraine, as well as pathological changes occurring in the organs of broilers during spontaneous ornithobacteriosis.

\section{Materials and methods}

All stages of research were carried out in accordance with the "European Convention for the Protection of Vertebrate Animals used for Research and Other Scientific Purposes" (Strasbourg, 1986) and approved by the Commission on Bioethics. The studies were carried out in 2019-2020, on the basis of the histological and bacteriological research sector of the Expert Center for Diagnostics and Laboratory Support "Biolights" (urbantype settlement Baryshevka), accredited in accordance with the requirements of DSTU ISO/IEC 17025:2017 according to No. 201864, and on the basis of the Laboratory of Immunomorphology of the Department of Anatomy, Histology and Pathomorphology of Animals named after Academician G. Kasiyanenko, National University of Life and Environmental Sciences of Ukraine (Kyiv).

For research, sick broiler chickens aged 25 days, with an average body weight of $1200 \mathrm{~g}$, were used. With the help of bacteriological studies, ornithobacteriosis was diagnosed in birds, which in some individuals was complicated by escherichiosis. For feeding the poultry, we used fullfeed compound feed produced by "Plakhtyanski Kormy". To select pathological material, in a state of light ether anesthesia, 5 sick broiler chickens were slaughtered and internal organs (lungs, kidneys, liver, trachea, spleen and heart) were taken for microscopic studies and tracheal washes for bacteriological studies. To identify the causative agents of pneumonia and aerosaculitis from a bird slaughtered in a state of light ether anesthesia, washes were taken from the tracheal mucosa using a sterile SWEB applicator of the Biomerieux trademark. Selected material from the tracheal mucosa was plated by direct inoculation on blood agar. Cultivation is carried out under microaerophilic conditions at $37{ }^{\circ} \mathrm{C}$ for 48 hours. After cultivation, the growth of small matt grey colonies was found. The 2-day culture was identified using the Maldi Tof direct mass-spectrometry method. The basic solvent (BS) was prepared from $475 \mu \mathrm{L}$ of ultrapure deionized water, $500 \mu \mathrm{L}$ of acetonitrile (ACN) and $25 \mu \mathrm{L}$ of $100 \%$ trifluoroacetic acid (TFA). To prepare the matrix, $250 \mu \mathrm{L}$ of basic solution (BS) was added to a tube with $\alpha$-cyano-4-hydroxy-brownic acid (HCCA).
The mixture was thoroughly mixed on a vortex for 5 min until complete dissolution. To verify compliance and peak intensity the instrument calibration was carried out with a Bruker Bacterial Test Standard 100\% Concentration (BTS) (Cat. No. 255343). A small amount of bacterial culture was applied in a thin layer to the surface of the target strip.

After drying, the dot was covered with $1 \mu \mathrm{L}$ of HCCA matrix solution, and an hour after its complete drying, detection was performed. Mass-spectrum were obtained using Maldi Tof in the mass range of $\mathrm{m} / \mathrm{z}$ from 3000 to 20,000. The SCiLS Lab software was used to collect spectra and identify peaks and analyze them. All settings and manufacturer's recommendations for standard treatment were used. The antibiotic sensitivity of the isolated microorganisms' culture was established using the disk diffusion method. From a pure daily culture, a suspension was prepared in sterile isotonic sodium chloride solution on a turbidity scale of 0.5 (McFarland).

The suspension was inoculated with Mueller Hinton blood agar Biomerieux medium, and disks with antibiotics were laid on the surface. Culture cultivation of the isolated microorganisms was carried out in Petri dishes at a temperature of $37^{\circ} \mathrm{C}$ for 24 hours. After cultivation, growth inhibition zones were measured according to CLSI: M31-A3 and Quality control limits for antibiotics based on results using Muller Hinton blood agar Biomerieux. For histological examination, the selected organ samples were fixed in a $10 \%$ solution of neutral formalin for 24 hours. The guiding was carried out using a semi-automatic histological processor Leica HistoCorePearl, according to the standard protocol of increasing concentration alcohols and xylene. Pouring into paraffin blocks was carried out at a Leica Arcadia pouring and cooling station. Finished paraffin blocks $5 \mu \mathrm{m}$ thick were cut using a Leica 2125RTS rotary microtome. Sections were stained with hematoxylin and eosin. Microscopy was carried out using a Leica DM 2000LED microscope and N PLAN plan-achromatic lens with $\mathrm{x} 10, \mathrm{x} 20, \mathrm{x} 40$ magnifications of a Leica MC170 HD camera, and Leica LAS X software.

\section{Results}

During clinical examination of sick broiler chickens, general depression, ruffled plumage, apathy and refusal to feed were noted. In some individuals, nasal discharge and edema of the nasal mucosa were observed. Bacteriological studies with the identification of Maldi Tof massspectrometry identified the isolated culture of microorganisms from the trachea as Ornithobacterium rhinotracheale. Based on the results of the antibiotic sensitivity test, it was found that the culture of ornithobacteria is sensitive to doxycycline, tilmicosin, rifampicin, cefazolin, amoxiclav and benzylpenicillin, moderately sensitive to enrofloxacin, and resistant to gentamicin and oxytetracycline (Table 1).

Table 1

Sensitivity of Ornithobacterium rhinotracheale culture isolated from the trachea of broiler chickens to antibiotics $(\mathrm{n}=3)$

\begin{tabular}{|c|c|c|c|c|c|c|}
\hline \multirow{2}{*}{ Antibiotic } & \multirow{2}{*}{$\begin{array}{l}\text { Antibiotic content } \\
\text { in the disk, } \mu \mathrm{g} / \mathrm{g}\end{array}$} & \multicolumn{3}{|c|}{ Results interpretation scale * } & \multirow{2}{*}{$\begin{array}{c}\text { Growth retardation } \\
\text { zone, } \mathrm{mm}\end{array}$} & \multirow{2}{*}{$\begin{array}{c}\text { Result } \\
\text { research }\end{array}$} \\
\hline & & resistant & moderately sensitive & sensitive & & \\
\hline Erythromycin & 10 & $\leq 20$ & $21-22$ & $\geq 23$ & $1.0 \pm 0.58$ & resistant \\
\hline Enrofloxacin & 10 & $\leq 18$ & $19-22$ & $\geq 23$ & $20.0 \pm 0.41$ & moderately sensitive \\
\hline Oxytetracycline & 30 & $\leq 24$ & _** & $\geq 24$ & $21.0 \pm 0.58$ & resistant \\
\hline Benzylpenicillin (Penicillin-G) & 10 & $\leq 17$ & $\_* *$ & $\geq 17$ & $19.0 \pm 0.33$ & sensitive \\
\hline Amoxiclav & 30 & $\leq 15$ & -** & $\geq 15$ & $27.0 \pm 0.58$ & sensitive \\
\hline Gentamicin & 30 & $\leq 23$ & $\_* *$ & $\geq 23$ & $7.0 \pm 0.58$ & resistant \\
\hline Cefazolin & 30 & $\leq 14$ & $15-17$ & $\geq 18$ & $21.0 \pm 0.58$ & sensitive \\
\hline Rifampicin & 15 & $\leq 16$ & $17-19$ & $\geq 20$ & $20.6 \pm 0.33$ & sensitive \\
\hline Doxycycline & 30 & $\leq 12$ & $13-15$ & $\geq 16$ & $19.7 \pm 0.33$ & sensitive \\
\hline Tilmicosin & 15 & $\leq 13$ & $14-20$ & $\geq 21$ & $21.3 \pm 0.30$ & sensitive \\
\hline
\end{tabular}

Notes: *-measurement results interpretation of growth inhibition zones in accordance with quality control limits for antibiotics based on results using Muller Hinton blood agar Biomerieux; ${ }^{* *}$ - the same numerical values of the limits for sensitive and resistant cultures, moderate sensitivity is not determined.

In the lungs, the lumina of most parabronchi were markedly reduced due to edema of their walls and infiltration, mainly by lymphocytes, among which there were a small number of monocytes and pseudoeosinophils (Fig. la, b). The epithelium on the surface of the parabronchi is almost completely absent. Only here and there were there single flattened epithelial cells or their small groups. Most of the air capillaries of all parabronchial complexes without exception were narrowed due to the expressive expansion and overflow of blood capillaries with blood. On the other hand, a small part of the air capillaries was clearly expanded (Fig. 1a, b), which may indicate a compensatory reaction of the lungs to the loss of a significant part of the gas exchange surface. The epithelium was also absent on the surface of many air capillaries (Fig. 1c).

All blood vessels of the lungs were clearly dilated, overflowing with blood cells. Around the blood vessels, in all cases, pronounced edema was 
shown, and around some of them there was also hemorrhage (Fig. 1d). Hemorrhages were also found in the parenchyma of the parabronchial complexes (Fig. 1c).

The trachea was markedly less affected than the lungs. The entire surface of the tracheal mucosa was covered with a rather thick layer of mucus (Fig. 2a). Some of the epithelial cells of the tracheal mucosa were
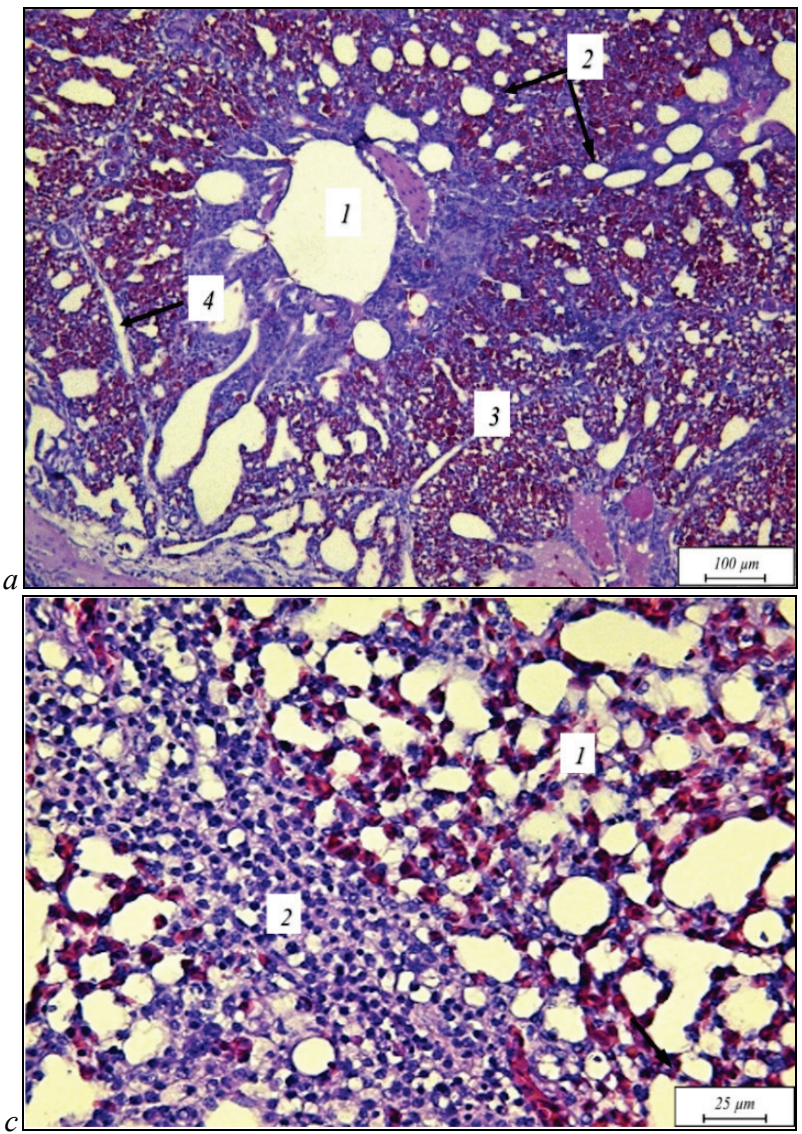

Fig. 1. Lungs of broiler chickens with Ornithobacterium rhinotracheale:

$a$-lumen of the parabronchus (1), dilated air capillaries (2), narrowed air capillaries (3), unevenly edematous connective tissue (4); $b$ - parabronchial lumen (1), absence of respiratory epithelium (2), lymphocytic infiltration; dilated capillaries full of blood (3), hemorrhage (4); $c$-absence of the airway capillary respiratory epithelium ( $(1)$, edema and lymphocytic infiltration of connective tissue between two adjacent parabronchial complexes (2); $d$ - dilated, blood-filled artery (1), edema and hemorrhage around the artery (2); hematoxylin gill and eosin
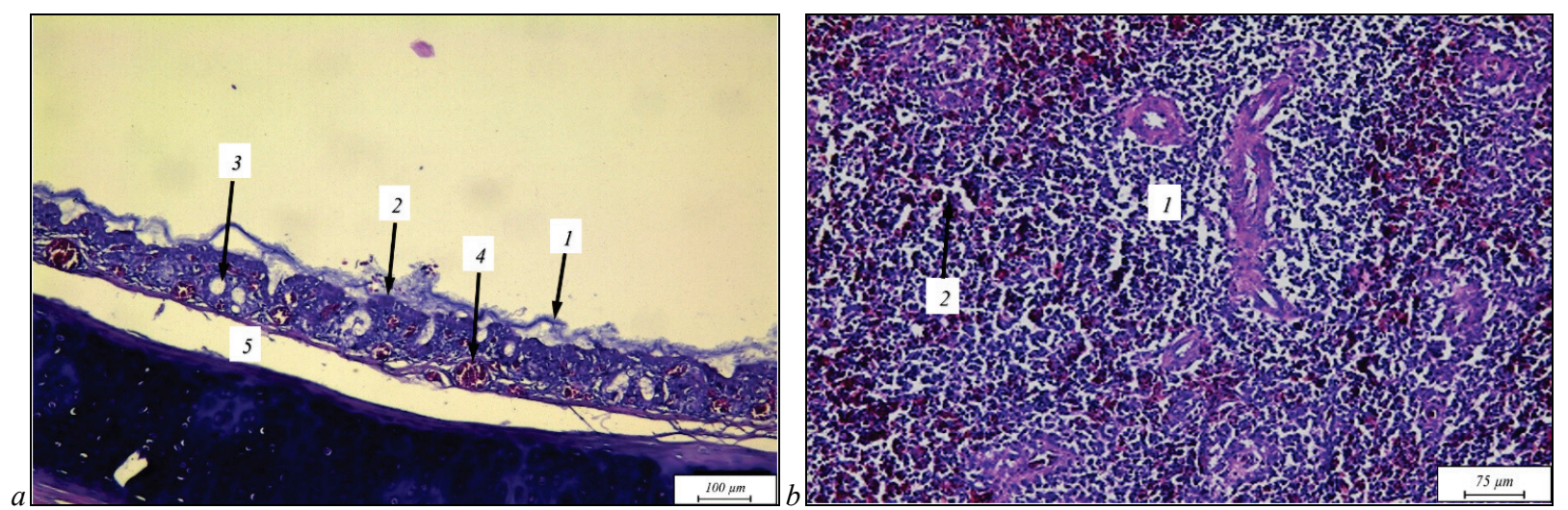

Fig. 2. Trachea $(a)$ and spleen $(b)$ of broiler chicken with Ornithobacterium rhinotracheale:

$a$ - mucus on the mucosal surface (1), destruction of the epithelium (2), foci of edema (3), dilated, blood-filled vein (4) edema of the submucosa (5);

$b$-Broiler chicken with ORT: lymphoid nodule emptying (1), parenchymal edema (2); hematoxylin gill and eosin

In the kidneys, the blood vessels of the stroma in most areas were clearly dilated, overflowing with blood. In places, hemorrhages were recorded (Fig. 3a). In part of the renal corpuscles, uneven edema of the glomeruli was recorded, accompanied by granular dystrophy of mesangiocytes and destruction of some of the podocytes. In the rest of the renal corpuscles, the glomeruli were partially or almost completely destroyed (Fig. 3b). Microscopic changes in the convoluted and rectal tubules of the kidneys were similar. Granular dystrophy of epithelial cells was revealed.
In some of the tubules, an expressive subepithelial edema was recorded, which led to the complete or partial separation of epithelial cells from the basement membrane. Changed due to dystrophy and completely or partially separated from the basement membrane of the tubules, epithelial cells were necrotic or destroyed (Fig. 3c). In some parts of the kidneys, in part of the convoluted and straight tubules, lysis of their basement membrane was observed, as a result of which this membrane completely or partially did not appear, and the epithelial cells of the tubules formed disor- 
dered clusters (Fig. 3d). The presence of expressive microscopic changes was found in the liver of chickens with ornithobacteriosis. The organ was diffusely swollen, with hemorrhages (Fig. 4a). Due to significant edema, the structure of many hepatic lobules was clearly disrupted. Part of the central veins and veins of the hepatic triads was significantly enlarged. Hepatocytes were in a state of granular degeneration or destroyed. Histo-
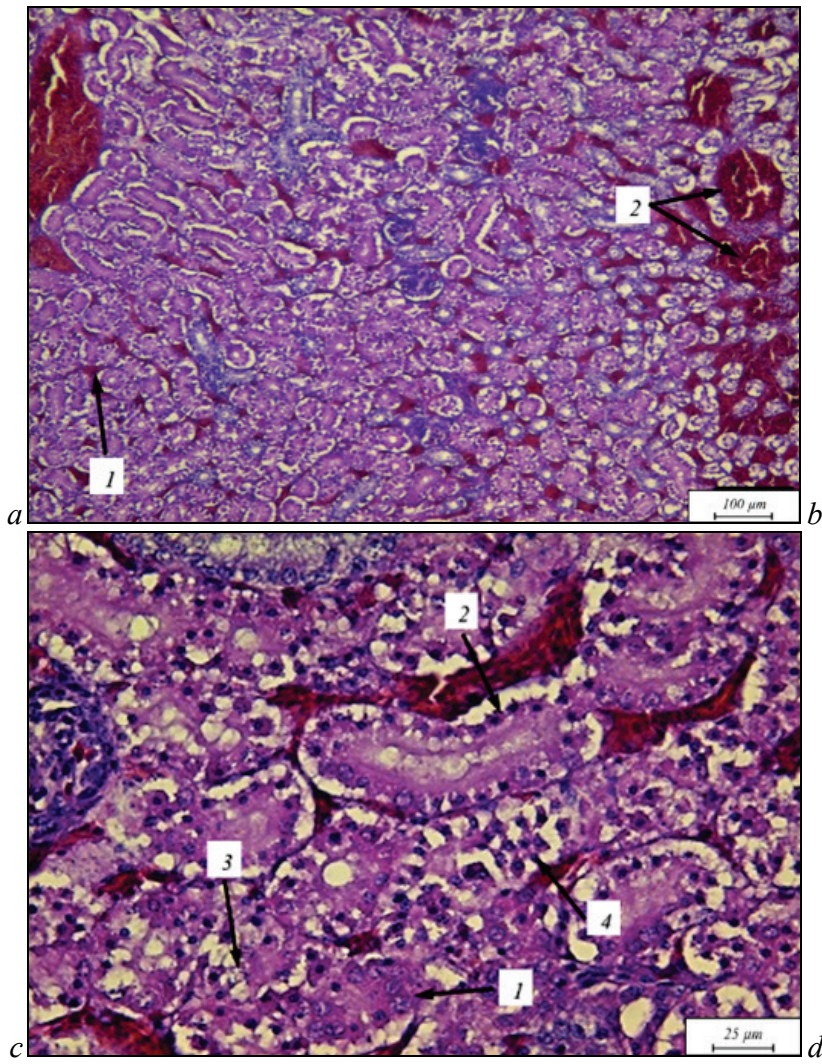

logical studies of the heart did not reveal microscopic changes in the endocardium and epicardium. But in the myocardium, a significant edema of the interstitium was revealed. All muscle fibers were in a state of granular degeneration. In some places, breaks of individual muscle fibers and their small bundles were recorded, as a result of which such fibers became fragmented (Fig. 4b).
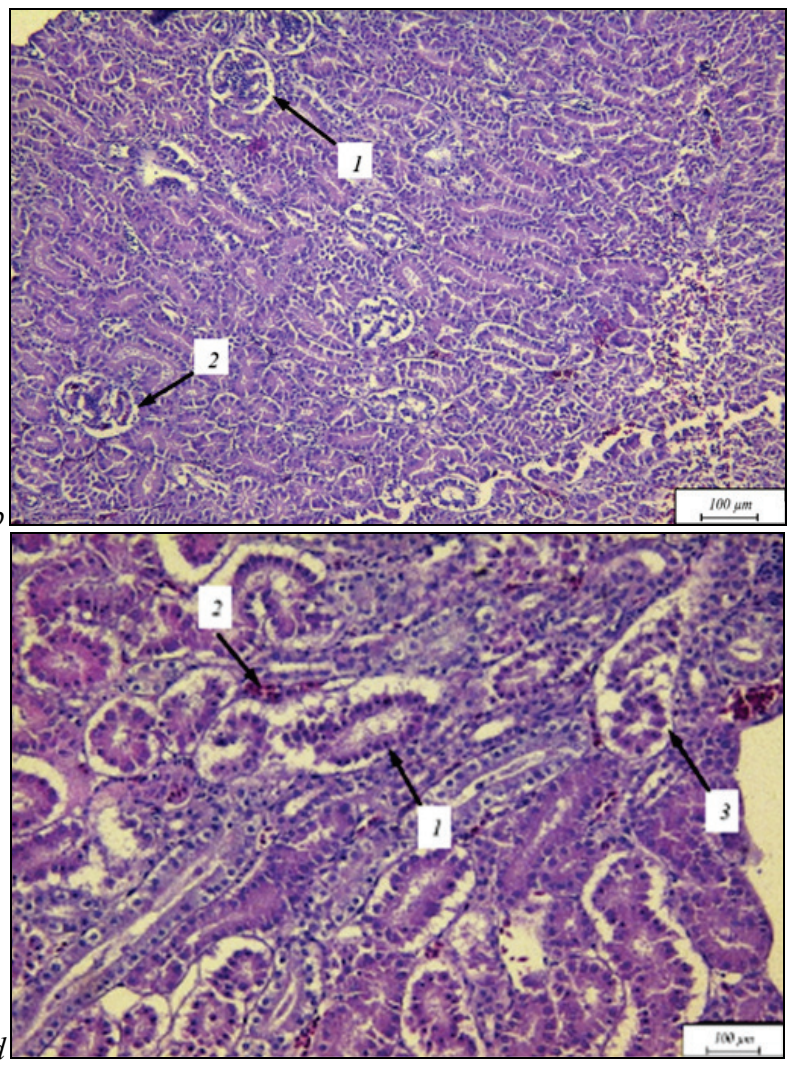

Fig. 3. Kidney of broiler chicken with ORT: $a$ - dilated, blood-filled blood capillaries of the stroma (1), hemorrhages (2); $b$-glomerular edema (I), destruction of the glomerulus (2); $c$ - granular degeneration of tubular epithelial cells (1), separation of the epithelium from the basement membrane (2), necrosis of epithelial cells (3), destruction of epithelial cells (4); $d$ - granular degeneration of tubular epithelial cells $(1)$, subepithelial edema (2), hemorrhage (3); hematoxylin gill and eosin
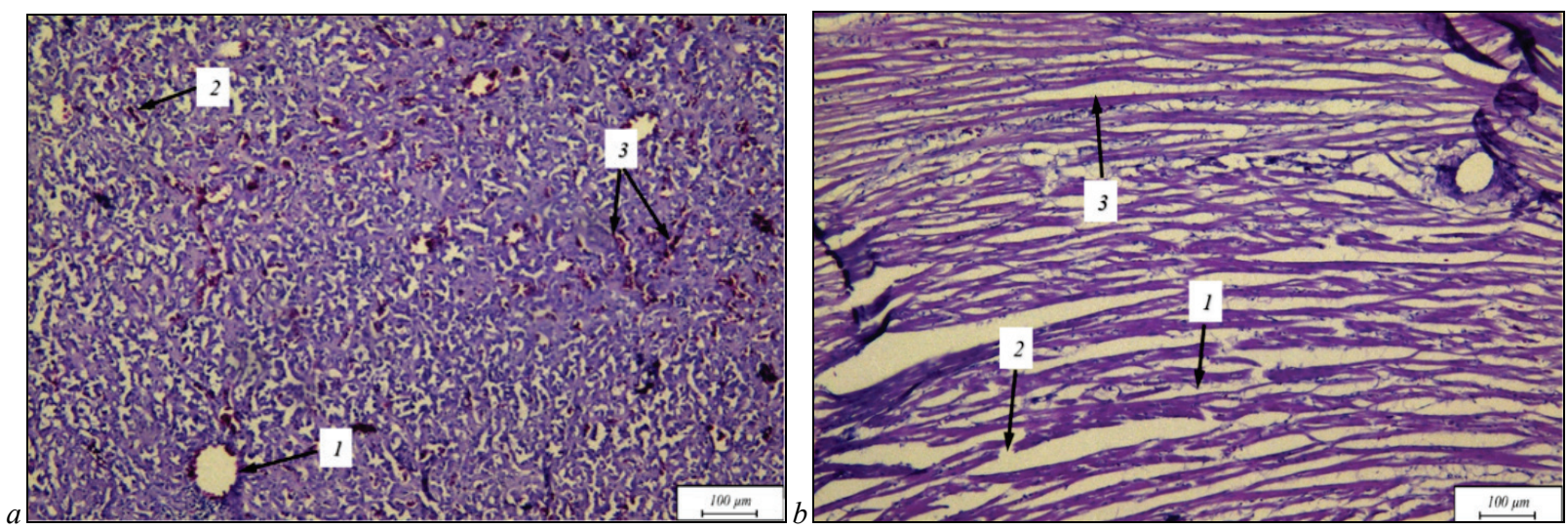

Fig. 4. Liver $(a)$ and myocardium $(b)$ of broiler chicken with ORT: $a$ - the central vein is definitely enlarged $(1)$; edema and disorganization of the structure of the hepatic lobules (2); hemorrhages (3); $b$ - granular dystrophy of muscle fibers (1); fragmentation of muscle fibers (2); interstitial edema (3); hematoxylin gill and eosin

\section{Discussion}

Bacteriological studies with identification by Maldi Tof mass spectrometry identified a culture of microorganisms isolated from the broilers' trachea as Ornithobacterium rhinotracheale. Bacteriological studies are essential for the diagnosis, since microscopic changes in a number of diseases can be similar. In particular, studies by Hany Ellakany and Hatem Hamid have established that similar microscopic changes occur for mycoplasmosis and ornithobacteriosis, and the causative agents of these disea- ses can develop together, mutually reinforcing the pathogenic effect (Ellakany et al., 2019).

To establish the diagnosis, the clinical signs of the disease and pathological changes were also taken into account. For spontaneous ornithobacteriosis of broiler chickens, the characteristic pathological signs are croupous pneumonia, focal fibrinous aerosaculitis, tracheitis, splenic hyperplasia, serous-fibrinous pericarditis, myocarditis, punctate hemorrhages, nephritic pleural effusion. Determination of the sensitivity of $O$. rhinotracheale to antibiotics is of great importance for the effective treatment of 
birds with ornithobacteriosis as well as preventing the development of antibiotic resistance.

When determining the sensitivity to antibiotics of the ornithobacteria culture isolated from the trachea of clinically sick broiler chickens, it was found that the causative agent of ornithobacteriosis is sensitive to antibiotics of various groups, in particular to penicillin, amoxiclav, cefazolin, rifampicin, doxycycline and tilmicosin (Table 1). A number of studies have established high activity against gram-negative and gram-positive bacteria, including against ornithobacteria and mycoplasmas, antibiotics from the macrolide and tetracycline's group. On the Ukrainian market for use in veterinary medicine tilmicosin has been proposed, which has a pronounced ability to accumulate in the lung tissue and maintain active concentrations for a long time, as well as doxycycline, a semi-synthetic antibiotic from the tetracyclines' group. Doxycycline exhibits a wide spectrum of antimicrobial activity, and the therapeutic concentration in the body is maintained for 24 hours (Kempf et al., 1997; Wafaa et al., 2009; Guttierrez et al., 2017). Histological studies have shown that with ornithobacteriosis of broiler chickens, microscopic changes occur in many organs. They were most expressive in the lungs, trachea, kidneys, somewhat less expressive in the spleen, liver and myocardium. In particular, in the lungs, a narrowing of the parabronchus was noted, which occurred as a result of edema and infiltration of their walls by lymphocytes, among which monocytes and pseudoeosinophils were found, which indicates the development of an inflammatory process. It is also worth noting the narrowing of most air capillaries of all parabronchial complexes, as a result of expressive expansion and overflow of blood capillaries with blood.

The expansion of a small part of the airway capillaries is considered as a compensatory reaction of the lungs to ensure gas exchange. The pathological process in the lungs was characterized by the almost complete absence of epithelium on the surface of the parabronchus and the surface of almost all air capillaries. Expansion of all blood vessels of the lungs, pronounced edema around them, and in some cases also hemorrhages were found. In the parenchyma of the parabronchial complexes, hemorrhages were also detected (Fig. 1). The described microscopic changes in the lungs of broiler chickens coincide with those found by Kotsyumbas and Blishch and spontaneous ornithobacteriosis of birds at the age of 28 days and the changes identified by Kilic \& Timurkaan $(2009,2010)$ in broiler chickens during experimental infection of ornithobacterium. The trachea is less affected than the lungs. The surface of the tracheal mucosa is covered with a thick layer of thick mucus, some of the epithelial cells of the mucous membrane are destroyed, and some become clearly flattened. As in the lungs, all blood vessels of the tracheal mucosa are dilated and overflowing with blood cells (Fig. 2a). Similar microscopic changes were observed in the trachea of 60-day-old quails with ornithobacteriosis, which were characterized by slight degeneration and desquamation of the mucosal epithelium, edema of the lamina propria, edema and congestion, hemorrhages of varying severity and incendiary cell infiltration (Kapakin et al., 2013). Other studies three days after experimental infection of broiler chickens aged 14 days with the causative agent of ornithobacteriosis established: tracheal mucosa with signs of catarrhal tracheitis, goblet cell hyperplasia, lymphocyte infiltration, loss of cilia, hyperplasia of the mucous membrane and glandular epithelium, stagnant phenolmena and infiltration by mononuclear cells (Ellakany et al., 2019). In the spleen, diffuse parenchymal edema and a decrease in the number of lymphocytes in lymphoid follicles were noted. With such changes, the cellular link of nonspecific immunity is significantly reduced (Fig. 2b). When examining the spleen of broiler chickens with spontaneous ornithobacteriosis, Kotsyumbas \& Blishch (2015) established moderate edema and dissociation tissue of the spleen capsule, pronounced vascular hyperemia and significant depletion of periarterial lymphoid sheaths, peri-ellipsoid muffs of the white pulp T and B lymphocytes. The presence should be noted of pronounced microscopic changes in various structural parts of the kidneys. In particular, the blood vessels in most parts of the stroma are dilated and overflowing with blood, irregular edema of the renal glomeruli, which was accompanied by granular dystrophy of the mesangiocytes and destruction of some of the podocytes.

In the convoluted and rectus tubules of the kidneys, granular degeneration of epithelial cells was observed. Complete or partial separation of epithelial cells from the basement membrane in part of the tubules is con- sidered the result of subepithelial edema. Some of the epithelial cells separated from the basement membrane experienced degenerative and necrotic changes were destroyed (Fig. 3). Expressive microscopic changes were found in the liver of broiler chickens with ornithobacteriosis. The liver is diffusely edematous, with hemorrhages. As a result of edema, the structure of the hepatic lobules was disturbed. The granular degeneration of hepatocytes and their destruction were found (Fig. 4a). Histological examinations of the heart revealed significant edema of the myocardial interstitium, granular dystrophy of muscle fibers, which is the cause of ruptures of individual muscle fibers and their small bundles (fragmentation of muscle fibers, Fig. 4b). Based on the studies carried out, we believe that with ornithobacteriosis of broiler chickens, an inflammatory process develops in the respiratory organs, which leads to a deterioration in gas exchange, which in combination with the effects of toxins that Ornithobacterium rhinotracheale secretes, leads to the development of multiple organ pathology.

\section{Conclusions}

With spontaneous ornithobacteriosis of broiler chickens, microscopic changes occur in the lungs, trachea, spleen, kidneys, liver and myocardium. In the lungs of broiler chickens with ornithobacteriosis, microscopic changes were characterized by a decrease in the lumen of the parabronchial tubes due to edema of their walls and infiltration, mainly by lymphocytes, the absence of epithelium on the parabronchus's surface; narrowing of the parabronchial complexes air capillaries due to the expansion and overfilling of blood capillaries with hemorrhages in the parenchyma of the parabronchial complexes; dilation of lungs' vessels, their overflow with blood cells and edema around the vessels.

Microscopic changes in the trachea of broiler chickens with ornithobacteriosis were characterized by the destruction of a part of the mucous membrane's epithelial cells, and the other part of them became distinctly flattened; swelling of the submucosa; expansion and overflow of mucous membrane's blood vessels with blood cells. In the spleen of broiler chickens with ornithobacteriosis, uniform diffuse edema and a decrease in the number of lymphocytes in the lymphoid follicles were established; in the kidneys - expansion and overflow of stroma's blood vessels, uneven edema of part of the glomeruli renal corpuscles and glomeruli destruction of the other, granular degeneration of the tortuous and straight tubules of the kidneys; in the liver - edema, hemorrhages, violation of the hepatic lobules' structure, expansion of the hepatic veins and veins of the hepatic triads, granular degeneration of hepatocytes or their destruction; in the heart edema of the myocardial interstitium, granular dystrophy of muscle fibers, fragmentation of muscle fibers as a result of their rupture.

\section{References}

Barbosa, E. V., Cardoso, C. V., Silva, R., Cerqueira, A., Liberal, M., \& Castro, H. (2020). Ornithobacterium rhinotracheale: An update review about an emerging poultry pathogen. Veterinary Science, 7(1), 1-13.

Chu, J., Zhang, Q., Zuo, Z. J., El-Ashram, S., Guo, Y., Zhao, P., Huang, S., He, C., \& Khan, A. (2017). Co-infection of Chlamydia psittaci with H9N2, ORT and Aspergillus fumigatus contributes to severe pneumonia and high mortality in SPF chickens. Scientific Reports, 7(1), 1-10.

Ellakany, H. F., Elbestawy, A. R., Abd-Elhamid, H. S., Gado, A. R., Nassar, A. A., Abdel-Latif, M., Ghanima, I., El-Hack, M., Swelum, A., Saadeldin, I., BaAwadh, H., \& Alowaimer, A. (2019). Effect of experimental Ornithobacterium rhinotracheale infection along with live infectious bronchitis vaccination in broiler chickens. Poultry Science, 98(1), 105-111.

Gavrilović, P., Gavrilović, A., Vidanović, D., Parunović, J., \& Jovanović, M. (2015). Comparative pathomorphological, bacteriological and serological examination of broiler breeders and pheasants experimentally infected with Ornithobacterium rhinotracheale. Avian Pathology, 45(5), 513-519.

Hauck, R., Chin, R. P., \& Shivaprasad, H. L. (2015). Retrospective study on the isolation of Ornithobacterium rhinotracheale from chickens and turkeys in central California: 294 cases (2000-12). Avian Diseases, 59(1), 130-137.

Kapakin, K., Büyük, F., Sahin, M., \& Kapakin, S. (2013). Respiratory tract infection induced experimentally by Ornithobacterium rhinotracheale in quails: Effects on heat shock proteins and apoptosis. Revue de Médecine Vétérinaire, 164(3), $132-140$. 
Kempf, I., Reeve-Johnson, L., \& Gesbert, F. (1997). Efficacy of tilmicosin in the control of experimental Mycoplasma gallisepticum infection in chickens. Avian Diseases, 4, 802-807.

Kilic, A., Timurkaan, N., Ertaş, A. A., \& Yilmaz, F. (2009). Pathological examination and bacterial re-isolation by culture and PCR of experimental Ornithobacterium rhinotracheale infection in broiler chickens. Revue de Médecine Vétérinaire, 160(3), 140-144.

Kotsyumbas, G. I., \& Blishch, G. I. (2015). Histopathological changes in chickens lund of Ornithobacterium rhinotracheale. Scientific Messenger of Lviv National University of Veterinary Medicine and Biotechnologies, Series Veterinary sciences, $61,78-82$

Kotsyumbas, G. I., \& Blishch, G. I. (2015). Histopathological changes in chickenbroilers spleen of Ornithobacterium rhinotracheale. Scientific Messenger of Lviv National University of Veterinary Medicine and Biotechnologies, Series Veterinary Sciences, 63, 66-70.

Kotsyumbas, G. I., Blishch, G. I., \& Shchebentovska, O. M. (2015). Pathological changes in chickens of Ornithobacterium rhinotracheale. Veterinary Medicine $100,149-152$

Mayahi, M., Gharibi, D., Ghadimipour, R., \& Talazadeh, F. (2016). Isolation, identification and antimicrobial sensitivity of Ornithobacterium rhinotracheale in broilers chicken flocks of Khuzestan, Iran. Veterinary Research Forum, 7(4), 341-346.
Morales-Erasto, V., Falconi-Agapito, F., Luna-Galaz, G. A., Saravia, L., MontalvanAvalos, A., Soriano-Vargas, E., \& Fernández-Díaz, M. (2016). Coinfection of Avibacterium paragallinarum and Ornithobacterium rhinotracheale in chickens from Peru. Avian Diseases, 60(1), 75-78.

Oca-Jimenez, R. M., Vega-Sanchez, V., Morales-Erasto, V., Salgado-Miranda, C., Blackall, P., \& Soriano-Vargas, E. (2018). Phylogenetic relationship of Ornithobacterium rhinotracheale strains. The Journal of Veterinary Medical Science, 80(6), 869-873.

Rosa-Ramos, M., Muñoz-Solís, K., Palma-Zepeda, M., Gutierrez-Castillo, A., Villegas, E., Guerra-Infante, F., \& Castro-Escarpulli, G. (2018). Adherence of Ornithobacterium rhinotracheale to chicken embryo lung cells as a pathogenic mechanism. Avian Pathology, 47(2), 172-178.

Szabó, R., Wehmann, E., Makrai, L., Nemes, C., Gyuris, É., Thuma, Á., \& Magyar, T. (2017). Characterization of Ornithobacterium rhinotracheale field isolates from Hungary. Avian Pathology, 46(5), 506-514

Wafaa, A., \& El-Ghany, A. (2009). The in-vitro and in-vivo evaluation of tiamulin and tilmicosin for the treatment of Mycoplasma gallisepticum infected broiler chickens. International Journal of Poultry Science, 8(12), 1189-1198.

Xue, J., Lv, C., He, P., \& Zhang, G. (2020). Serological investigation of Ornithobacterium rhinotracheale infection in China. Poultry Science, 99, 10. 